\title{
The Lived Experience of Anxiety Disorder Patients: Narrative Inquiry
}

\author{
Abiola Bamijoko-Okungbaye ${ }^{\varpi}$ \\ DOI: http://dx.doi.org/10.15294/jhe.v5i2.38348
}

Sofia University, Bulgaria

\section{History Article}

Submitted 17 April 2020

Revised 28 August 2020

Accepted 27 September 2020

\section{Keywords}

anxiety disorders; community; mental health; mental disorders; phenomenology

\begin{abstract}
Background: Anxiety disorder patients tend to feel that they are misunderstood and judged. Their lived experiences were understudied in clinical setting where the focus is mostly on their response to treatment. Apart from the stigma associated with the disorder, they face negative social perceptions, which affect their ability to interact with their community, disrupting their healing path. A narrative account in mental health can lead to the creation of a healthier society. This research examines how people with anxiety disorders view themselves and ascribe meaning to the stigma surrounding their condition.

Method: A narrative analysis of case studies in Europe, each patient sharing their in-depth lived experiences with anxiety disorders.

Results: Nadir's experience was initially expressed and as the participants gained a moderate, balanced level of self-awareness through narrative approaches, they quickly develop coping strategies that are essential to their recovery.

Conclusion: Narrative mental health might be an area that needs refocusing during the treatment of anxiety disorders patients.
\end{abstract}

\section{How to Cite}

Bamijoko-Okungbaye, A. (2020). The Lived Experience of Anxiety Disorder Patients: Narrative Inquiry. JHE (Journal of Health Education), 5(2), 55-60. $\triangle$ Corresponding Author:

Tsar Osvoboditel Blvd.,Sofia, Bulgaria

E-mail: bamijoko@yahoo.com
p-ISSN 2527-4252

e-ISSN 2528-2905 


\section{INTRODUCTION}

In the light of heightened COVID-19 pandemic when the world technically shut down to prevent the spread of the virus, coronavirus anxiety spiked dramatically. People with existing anxiety disorders find themselves in a difficult situation, making them vulnerable and overwhelmed dealing with the news coverage of the virus (Ettman et al., 2020; Hacimusalar et al., 2020). Globally, 284 million people experienced anxiety (Hannah \& Roser, 2018). Another closer look at this data is the fact that $75 \%$ of mental conditions in developing nations are not treated. Increased anxiety has consequences for stress levels and reduces the activity of the immune system and also a predictor for depression, high alcohol consumption (Nechita et al., 2018; Kalin, 2020). It is even possible for anxiety disorder patients to generate symptoms of other medical conditions, putting them at a disadvantage when it comes to the overall quality of life in comparison to others.

People with anxiety disorders need support for recovery and treatment. However, those on medications are psychologically processing the social stigma they face in their social life (Ociskova et al., 2013; Schofield et al., 2020). It is likely they face additional challenges with the existence of the negative perception of their condition within their social world (Blöte et al., 2014).

In addition to the stigma associated with having anxiety disorders, patients are likely to suffer from disruptive daily events. For example, socio-emotional challenges, such as getting groceries that people generally take for granted and daily social intercourse can become problematic because of their conditions which decreases their quality of life and well-being (Nikoli, 2020).

For these reasons, narrative inquiry is needed to examine their lived experience in order to gain insight into their lives and understand the societal challenges they face daily (Ghavami et al., 2014; Ghorbani \& Raeisi, 2020; Ravan \& Esfandeyari, 2016). Patient's experiences are the key to unlock the reason behind the social exclusion of patients, as a result of the disorder.

The goal of this research is further to expand this domain of narrative inquiry in mental health and to enhance our understanding on how anxiety disorder patients with self-awareness about the stigmatization develop personal understanding when they apply meaning to their situation. Moreover, this study intentionally detaches from employing statistics to explain the lived world of patients, as the goal is to grasp experiences of anxiety disorder patients as they cope with their conditions daily, that is, their lived experience interpreted and explained using their own words.

\section{METHODS}

Narrative inquiry in this study aims to provide lived experiences and interpretation of anxiety patients' experiences using their own words, allowing them to speak for themselves and avoiding the distorting effect of neuro essentialism representation; this can be empowering. Participants were approached offline and online, employing non-probability sampling. Participants over 18 were contacted by the author who built a rapport with the participants over two years. Those who agree to take part were provided information about the intent of this study. The observation was conducted to establish trust with interested participants by participating in shared activities. Participants were informed that the findings would be made public and confidentiality would be kept.

Besides, they were also advised not to answer the questions, if they feel uncomfortable-all procedures approved by the board of the nonprofit organization the author is affiliated with. Due to the nature of the questions and life story technique used in this interview, collation of data took several days for each participant. Data were collected on a digital device and all names are replaced with pseudonyms and identifying information changed to protect participants. Seven extensive interviews were conducted with participants between the age of 21-35 who have been suffering from anxiety disorders for over a year. The study included four women and three men, and they all self-identified as Europeans (n-7). From the participants, the stories of Jessica and James (34yrs, 25yrs) were selected because their stories captured the emergent themes and patterns which reflect across all participants.

\section{RESULTS AND DISCUSSIONS}

\section{Jessica's Story: "But To Be Honest, Without \\ This Network I've Made In Here, I Would \\ Have Been Just Isolating Completely. So In \\ That Way, I'm Kinda Lucky :)"}

Jessica was going to be 34 years when she participated in this research and was diagnosed when she was 17 years old with severe anxiety. She recalled the first time she had her first breakdown:

I couldn't walk on the streets anymore without thinking I would die. So I was admitted to a 
psych ward for a month. It only made everything worse, though. But that's when I was diagnosed with severe anxiety.

Noticeably, Jessica anxiety experience begins with this distressed mode, but Jessica's coping skills improved when she developed the capability to tell her story, which changed the dynamic of her experience. Her description of her first breakdown, comparing it to death was actually from a position of strength, that is, showing how strong she is and even though her past was not based on a positive experience. Still, her ability to speak for herself gave her a different outlook:

After years of therapy, I finally opened up, and my mental health practitioner helped put words on what had happened to me. I............... I don't think my life has changed, after getting diagnosed at 17, it turned already at 9.

In this description, Jessica alludes to the importance of the narrative approach in mental healthcare as the key to find a meaningful connection to the past and present. Through this narrative technique, one recognizes a pattern, that is, the shift from feeling estranged from the world to understanding that she belongs to the shared settings, a resilient theme was identified, her ability to see the good in the bad. So therefore, reaching a crucial stage in her recovery process. The attainment of this skill gives her a moderate level of balanced self-awareness; she used her gained awareness through therapy to explain the burden she might be putting on her social connections:

I'm almost 34, and I still have my mum and dad, take me to doctors' appointments, help me do laundry, grocery, and shopping e.t.c. And they both turn 70 this year, so it really should be the other way around.

The narrative sequence from being in a place of not saying nothing to a position of attainment of moderate level of balanced selfawareness is pretty redemptive and support the notion, that is, re-establishing meaningful connection aids recovery, all within the contemporary ampliative understanding of mental condition. Her painful awareness of a distressing past and calmly using her words to describe it, is a sign of empowerment:

I used to be a bit of a wild child...... Loved climbing trees, mountains and ropes. I took singing, dancing and piano and I knew my stuff at school....... But I think at age 12, I had to give it all up. I ..............so the burden of carrying it alone, got too heavy, I guess.

Here again, Jessica's take shows that narrative technique might have helped, if she would have been able to share her experiences. Still, mo- derate, balanced self-awareness theme is recognized in this context and continues to show throughout her explanation. Narrative techniques seem to be beneficial to Jessica, as she continues in this context. "In here, I try to end the stigma, I talk about all the things you're not supposed to talk about. That has actually helped me a lot, in my actual life, to be more open and honest, also less embarrassed." Her moderate, balanced self-awareness level after engaging in therapy shows that she can get herself to the driver seat and change the dynamic of her own story, this recurring agency in her narrative construction is fundamental to her recovery. Because she now possesses the ability to reconstruct a present narrative that allows her to have a fulfilled future narrative that was missing when she was first admitted to the psych ward. Jessica is getting to understand that she can now control the controllable, and the past was the past.

Throughout her engagement with this researcher, she remains optimistic about the future and even though she is still coping with the challenges that anxiety disorder brings:

Iexperience anxiety several times a day...... panic attacks. A challenging day would be one where I have to go out and meet people in a public place meeting strangers. Buying groceries, and doing laundry and honestly, everything that has to do with other people. That's why I'm by myself a lot.

Besides, the critique of the societal construct and the negative societal perception towards her condition is the development of coping techniques towards the stigma that still exists in our society. The moderate, balanced level of self-awareness, she obtained during her narrative engagement with her practitioner helps her in developing stigma management skills which are cardinal to her rediscovery's path:

People who doesn't understand anxiety doesn't understand why I can be so scared of so many things. Also, in the world, we live in today, it's difficult to be different. I......... and I don't have many friends because I don't really get out and meet any.

In brief, the lived experience, that is, the life story, as described by Jessica, illustrates the ability to develop a moderate level of balanced self-awareness after employing a narrative method in treatment. Jessica rejects the notion that social norms cannot be challenged; she asked to be allowed to be different, demanding a well-balanced societal norm. This can be achieved when we listen to those suffering amongst us. Allowing Jessica to express herself can be seen as providing valuable information in combating anxiety disorders. She developed a resilient narrative through 
the attainment of a moderate, balanced level of self-awareness and constructed a new counternarrative as her new gained steady self-awareness puts her in control of her future endeavour.

\section{James's Story: "Life's Story is Hardly Straight- forward".}

James had a rough background growing up; he explained, growing up in a home where his father abused drugs. For him, that was one of the low points in his life "It is like living in hell". In this expression, James perceived his home as a place where he would rather not be:

In the beginning, I thought I could be like my mates, scared that my........... as a kid growing

up, normality becomes a dream, something difficult to reach. I started doing......... I wanted to do things that ordinary people do. With the ups and lows of growing up, I was diagnosed with anxiety at 20 and was under medication. I can recall very well when $I$ convince myself that going out was not going to be a big deal. I ended up having a panic attack.

In this story, we notice the low point that James described is also similar to Jessica's experience; that is, a nadir experience. At this initial stage, James was still finding ways to make his anxiety disorders meaningful:

They sent me to therapy and did not think that it was what I needed at that time, as the therapy advances I noticed I have just been worrying about minor things which cause me to struggle and avoid peopleoverthinking things over and over as I believed that I had made a mockery of myself during those episodes.

James's narrative implies that he now applies meaning to his anxiety disorder by developing a moderate, balanced level of self-awareness which was recurring with all the participants in this study. His resilient theme and his gained moderate, stable level of self-awareness continued to show when he says:

Sometimes, I have my ups and downs, don't we all do? I just put myself in the position that I think of things I am thankful for. I hope that expressing my experience on this platform changes the negative societal perception people have with anxiety disorder patients.

Employing this narrative, James transitioned from not understanding his condition to a stage that he can articulate his experiences into something positive, again showing the resilient theme like the other cases presented in this study and what is noticeable is the stigma management skills that he developed after partaking in narrative therapy.

The objective of this study is to examine the lived experiences of anxiety disorder patients to shed light on how they construct their narrati- on in the face of their conditions and societal stigma that still exists around the globe today. A narrative approach is apt to deal with the questions asked in this study because it allows participants to describe their lived experiences. They also explained what equity in mental health looks like for them. The analytic framework employed by the author shows how anxiety disorder patients view themselves in the face of societal constructs. The stories show the theme of nadir experience and negative past, which reduced their quality of life.

These narratives reveal the negative societal constructs and the challenges they face; effecting change requires our collective effort. As Jessica puts it, society should understand that patients with anxiety disorders may be different because of their conditions, but they also belong to the shared societal shared setting. James mentioned that being yourself can take you far when fighting anxiety disorders.

These participants embrace the fight to end the stigma by not allowing the conditions to define them solely. Their moderate, balanced level of self-awareness attained during treatment improves their state of mind as Jessica pointed out: "In here, I try to end the stigma". Each of the narratives revealed the moderate, balanced selfawareness level after narrative therapy as James says: "It was helpful that I got the help when I was diagnosed with anxiety and sharing my experiences is to encourage others to seek help."

This shows that participants refuse to succumb to the societal construct that seems to make them feel detached from shared settings. The usual self-awareness pattern that is evident across all participants in this study shows that they are on the right path to define their future. One can also view the self-awareness achieved through narrative method allows them to question the negative societal perception of their conditions. A key point in this study surrounding how patients ascribe meaning to the negative societal construct that comes with the stigmatization of anxiety disorder patients. They point out that a mental health literate society would be helpful for their cause, so therefore, speaking out is the right way to end the stigma. Another point that was not expected at the initial start of the research, is the presence of agency in their description, that is, their attempt to carve a fulfilled future for themselves. Jessica explains, that opening up has allowed her to feel less embarrassed about her condition. Again we notice a moderate, balanced level of self-awareness which helped her in developing resilience and coping strategy (Edraki et al., 2018; Morales \& Pérez-Mármol, 2019; Zimmer-Gembeck et al., 
2018). The attainment of a reasonable, steady level self-awareness through narrative experiences of participants in this study is similar to studies that show that narration techniques in therapy can provide mental health growth and healing for patients who have mental conditions (Dein, 2016; Rickwood \& Bradford, 2012). With anxiety disorders, patients' narratives can reveal the locus of healing which the practitioner can expand on during practitioner-patient interaction (Yue-Gu, 2018; Gemignani, 2011).

Participants were informed that this study would be made public; this could have influenced their answers. These cases chosen in this study might not apply to all patients with anxiety disorders using a narrative technique as part of their treatment. This research aims to present a diverse valid representation of how anxiety disorder patients apply meaning to their experiences. The author's goal is not to give a reductionist account of their experiences, but to focus on the meaning the participants ascribed to their conditions clinically and socially.

\section{CONCLUSION}

The lived experiences of participants have provided insights that can be beneficial when making clinical decisions. This research has provided an opportunity for patients struggling with anxiety disorders to construct their narratives addressing the issues of stigmatization which is a societal construct and their attempts to change the status quo using their voice to construct their healing path. The attainment of a moderate, balanced level of self-awareness has created a gateway to manage the stigma, allowing them to develop coping mechanisms which eventually lead to their healing.

\section{REFERENCES}

Blöte, A. W., Miers, A. C., Heyne, D. A., Clark, D. M., \& Westenberg, P. M. (2014). The relation between social anxiety and audience perception: Examining clark and wells' (1995) model among adolescents. Behavioural and Cognitive Psychotherapy, 42(5), 555-567.

Dein, S. (2016). Narratives and Healing: Implications for Psychiatry and Psychotherapy. Anthropology, 4(1), 162.

Edraki, M., Rambod, M., \& Molazem, Z. (2018). The effect of coping skills training on depression, anxiety, stress, and self-efficacy in adolescents with diabetes: A randomized controlled trial. International Journal of Community Based Nursing and Midwifery, 6(4), 324-333.
Ettman, C. K., Abdalla, S. M., Cohen, G. H., Sampson, L., Vivier, P. M., \& Galea, S. (2020). Prevalence of Depression Symptoms in US Adults Before and During the COVID-19 Pandemic. JAMA Network Open, 3(9), e2019686.

Gemignani, M. (2011). The past if past: The use of memories and self-healing narratives in refugees from the former Yugoslavia. Journal of Refugee Studies, 24(1), 132-156.

Ghavami, M., Sadeghi, H., \& Mohammadi, E. (2014). The Effectiveness of Narrative Therapy on the Decrease of Social Phobia in the Female High School Students: Isfahan. International Journal of Academic Research in Business and Social Sciences, 4(9), 469-477.

Ghorbani, R., \& Raeisi, Z. (2020). The Effect of Narrative Therapy on School Anxiety in Female Primary Students. Quarterly Journal of Child Mental Health, 6(4), 168-178.

Hacimusalar, Y., Kahve, A. C., Yasar, A. B., \& Aydin, M. S. (2020). Anxiety and hopelessness levels in COVID-19 pandemic: A comparative study of healthcare professionals and other community sample in Turkey. Journal of Psychiatric Research, 129(August), 181-188.

Ritchie, H., \& Roser, M. (2018). Mental health. Our World in Data.

Kalin, N. H. (2020). The critical relationship between anxiety and depression. American Journal of Psychiatry, 177(5), 365-367.

Morales, F. M., \& Pérez-Mármol, J. M. (2019). The role of anxiety, coping strategies and emotional intelligence on general perceived self-efficacy in university students. Frontiers in Psychology, 10(JULY), 1689.

Nechita, D., Nechita, F., \& Motorga, R. (2018). A review of the influence the anxiety exerts on human life. Romanian Journal of Morphology and Embryology, 59(4), 1045-1051.

Nikoli, M. (2020). Social emotions and social cognition in the development of social anxiety disorder. European Journal of Developmental Psychology, 17(5), 649-663.

Ociskova, M., Prasko, J., \& Sedlackova, Z. (2013). Stigma and self-stigma in patients with anxiety disorders. Activitas Nervosa Superior Rediviva, 55(1-2), 12-18.

Ravan, A., \& Esfandeyari, M. (2016). The Role of Narrative Therapy in Reducing Social Anxiety and Improve Social Interactions. International Journal of Philosophy and Social-Psychological Sciences, 2(3), 41-46.

Rickwood, D., \& Sally Bradford. (2012). The role of self-help in the treatment of mild anxiety disorders in young people: an evidence-based review. Psychology Research and Behavior Management, 5, 25-36.

Schofield, C. A., Abdul-Chani, M., \& Gaudiano, B. A. (2020). Impact of causal explanations for social anxiety disorder on stigma and treatment perceptions. Journal of Mental Health, 29(1), 84-91.

Yue-Gu. (2018). Narrative, life writing, and healing: 
Abiola Bamijoko-Okungbaye / Journal of Health Education 5 (2) (2020) 55-60

the therapeutic functions of storytelling. Neohelicon, 45(2), 479-489.

Zimmer-Gembeck, M. J., Skinner, E. A., Modecki, K. L., Webb, H. J., Gardner, A. A., Hawes, T., \&
Rapee, R. M. (2018). The self-perception of flexible coping with stress: A new measure and relations with emotional adjustment. Cogent Psychology, 5(1), 1-21. 